\title{
Invited Commentary: Societal Constraints and Individual Agency: Navigating Educational Transitions for Upward Mobility
}

\author{
Jutta Heckhausen (iD ${ }^{1}$
}

Received: 20 August 2020 / Accepted: 22 August 2020 / Published online: 5 September 2020

(c) Springer Science+Business Media, LLC, part of Springer Nature 2020

\begin{abstract}
This article discusses three empirical studies of the role of individual agency in educational transitions in the conceptual framework of the motivational theory of lifespan development that integrates life-course sociological and life-span psychological perspectives. The educational systems in the U.K., the US, and Switzerland set up specific opportunities and constraints in their primary to secondary and secondary to tertiary educational tracks. Individual agency plays out in different ways in these country- and transition-specific fields of action and accordingly enables or hinders individual youths' upward mobility. Early transitions into segregated secondary school systems are dominated by the influence of teachers and parents and tend to maintain social inequality. Later transitions into tertiary education are more open to individual agency that can substantially contribute to overcoming social inequalities in college admission. Finally, once enrolled in university, students have comparatively better opportunities to overcome disadvantages of their parents' socio-economic status and educational background.
\end{abstract}

Keywords Agency $\cdot$ Motivation $\cdot$ Educational transitions $\cdot$ Comparisons between US, UK and Switzerland

\section{Introduction}

The three articles in this special issue address the potential influence of individuals on their own upward mobility, specifically how individuals can use their own agency to do better than expected given their socioeconomic background. How can individuals achieve a life-course trajectory that is better than would be expected based on their socioeconomic origins? The intriguing focus of these articles is on agency in the face of two impactful educational transitions, from primary (elementary school) to secondary (lower vs. upper-tier of high school), and from secondary to tertiary (vocational training vs. 2-year or 4-year college) education. The three countries (Switzerland, UK, and USA) addressed in this set of articles may be somewhat similar in the big scheme of global comparisons, but their educational systems set up unique conditions at these two critical transitions, and as a result the control of these transition outcomes shifts to different people (e.g., teachers or parents

\footnotetext{
Jutta Heckhausen

heckhaus@uci.edu

1 University of California, Irvine, CA, USA
}

or student), and to different agency resources of the individual student. Before getting into these specific societal conditions, the dynamic between individual agency and social structure is discussed in a more general conceptual way. Numerous factors play into this, only some of which can be investigated in a limited set of studies as included in this special section. Hence, it is important to delineate the lay of the land conceptually, so as to better identify where the pieces of the puzzle addressed in this set of empirical studies fit in the bigger picture of agency in educational transitions that are key to social mobility.

\section{Societal Structure and Individual Agency}

Different disciplines in the social and behavioral sciences view the potential for individual agency for social mobility in contrasting ways. From a psychological perspective, the individual agent is emphasized and the influence of the individual on shaping their own development is amplified. In contrast, disciplines that focus on society, its institutions and structure of social inequality, emphasize the stabilizing mechanisms in a society's social inequality. The solution to this puzzle is to integrate the perspectives from multiple disciplines, specifically life-course sociology and lifespan developmental psychology, and identify the specific 
conditions that allow versus constrain individual agency (Heckhausen 2016; Heckhausen and Buchmann 2019). This involves addressing the specific obstacles that stand in the way of moving out of a canalized life path and step over to a path that leads to upward mobility, and to identify the individual characteristics that enable the individual developmental agent to overcome these obstacles (Heckhausen and Buchmann 2019; Heckhausen et al. 2019).

In modern industrialized societies, individuals' paths into adulthood involve age-normative institutionalized steps of education and training to enter vocational or professional careers. Particularly, the educational components of these normative paths are highly prescriptive, and in recent decades and some countries (e.g., United States, European countries) tertiary education has become a prerequisite for nearly any career that exceeds un-skilled labor. With the role of higher education amplified, the pressure from those on the upper rungs of the social ladder have increased to hold onto and expand privileged access for their offspring in order to secure their elevated position on the social ladder. For example, in a thorough analysis of historical trends (1951-2012) of social origin-education and educationoccupation relationships, Pfeffer and Hertel (2015) show for the case of the United States that gains in intergenerational mobility for college graduates from diverse SES backgrounds are counter-balanced by long-term historical increases in social inequality for college access. In different societies, these social inequalities in access to secondary and tertiary education is taking different forms. It is at the transition points from elementary to secondary and from secondary to tertiary education, that social inequality in access is playing out. The mechanisms involved here are crucial for our understanding of who gains privileged access how, whether and how individuals from lower ladder rungs are excluded, and whether and how such exclusions or hindrances can be overcome by the efforts of individual agents striving to ascend the social ladder in their own life courses (Schoon and Heckhausen 2019).

Following an action-theoretical and motivational conceptualization of developmental agency, the motivational theory of lifespan development (Heckhausen et al. $2010,2019)$ views the individual as navigating an agegraded and sequentially organized action field of opportunities and constraints, that is organized into different paths for people of different socioeconomic origin. The default expectation is that the individual follows the normative path for their social class. It takes extra agentic efforts to step out of the commonly prescribed path and enter a different path associated with higher socioeconomic background.

The best opportunities to break out of such path dependencies is during transitions from one educational or employment institution to another (Heckhausen and Buchmann 2019). Here the individual can introduce aspirations and set goals for themselves that exceed the normative path. Of course, this takes stronger motivational direction and commitment than following the commonly assumed path. So as a consequence, individual differences in such motivational characteristics as goal selection and goal setting, as well as goal pursuit (e.g., persistence after failures or setbacks), and he capacity to identify and adjust to major and unsurmountable road blocks by disengaging from overambitious goals and re-engaging with attainable goals, play a greater role during these transitions than during other segments of the life course (Heckhausen and Wrosch 2016). However, it is not always the individuals themselves who are the critical agent during these transitions. During earlier parts of the lifespan, the decisive agents may be parents and sometimes even teachers (e.g., Ditton and Krüsken 2006).

\section{Degrees of Social Mobility}

What counts as success in life is a function of a society's culture and social structure. Inter-generational upward social mobility between the family of origin and the young person's socio-economic future is viewed differently in different societies in terms of its desirability and feasibility. Degrees of social mobility can range from the least to the most ambitious. The full range from least to most ambitious covers the following levels: (1) earning an income one can survive on, (2) attaining the same social status as one's parents, (3) attaining the same SES as one's parents but with better standard of living, (4) substantial yet manageable upward mobility (i.e., worker to professional), (5) extreme upward mobility ("rags to riches").

Actual upward mobility is rarely one of major jumps as in "rags to riches." In societies with relatively extreme inequality (e.g., India, Gini 47.9 Knoemacom), even steps up the social ladder are virtually impossible. An example from India are the unsurmountable barriers for members of the rural and low caste to move into professional positions such as in engineering careers (Krishna 2014). In the three countries considered in this special section, income inequalities are in the substantial yet relatively moderate range (.29 to .39), yet there are differences, in that Switzerland has a relatively moderate Gini coefficient (.30 in 2018) and USA and UK somewhat higher inequality indicators (Gini 0.39 and 0.36 resp.; source OECD data, see Fig. 1. https://data.oecd.org/inequality/income-inequality.htm).

For lower SES offspring in countries with high social inequality (e.g., USA), the path to upward mobility holds some formidable and close to unsurmountable barriers (e.g., cost of higher education even in countries with low college tuition, Becker and Hecken 2009). However, even maintaining working class status nowadays requires substantially more education from today's young adults than for their parents' generation. For the offspring of the professional 
upper middle class in countries with substantial and moderate social inequality (e.g., US, Germany, UK), the immediate challenge facing youth at the transition to adulthood is not so much upward mobility, but maintaining their parents' social status. In order to avoid downward status mobility, upper middle-class children need to ascend through a sequence of multiple educational institutions, to enter and establish a successful professional career (Diewald et al. 2016; Hahn 2016).

The set of articles in the special section addresses educational transitions relevant for the more feasible and common inter-generational upward mobility, namely from dependent worker without college to professional with college. In modern societies, social mobility is inextricably linked to success in navigating the multi-level educational system in order to gain access to higher level careers, incomes and social influence, and this in turn reflects the society's subscription to the notion of meritocracy. Social barriers to the higher levels of education, training and career render the notion of meritocracy problematic from a normative viewpoint (Littler 2017), yet both the educational and career pathways and the social barriers involved form the societal landscape for the individual agent and strongly shape their choices and action. In other words, even though the educational system with its transition and access restrictions is consistently biased to privilege the offspring of the already privileged (Breen and Goldthorpe 2001), individuals have no choice but to put their best effort into navigating the existing system to optimize their own lifecourse outcomes. Their success is, albeit canalized by social class differences, nevertheless partly a function of their individual talents, goal-setting acumen, and motivational self-regulatory capacities, and thus ironically supporting the meritocratic narrative of life-course success.

\section{What Does it Take to Achieve Worker to Professional Upward Mobility?}

Attaining a college degree requires managing the earlier transitions into high school and into college, institutions that impose a variety to gate-keeping obstacles to entry, differing by country. The three articles in this special issue elucidate these transitions and the relevant agency resources from different perspectives reflecting the educational systems in Switzerland (Buchmann et al. 2020), the United Kingdom (Schoon and Cook 2020), and the United States (Lee and Mortimer 2020). Switzerland (like Germany) has an educational system that involves an early transition into segregated secondary schools. In Switzerland the segregation happens after 6th grade (in Germany typically between 4th and 5th grade). Due to the relatively young age of the children, they themselves play no legal role in choosing their secondary school. It is up to the teachers to make recommendations that then can be challenged by parents to a varying degree in different states. Given the prominent role of teachers in regulating this transition, one might expect that the critical characteristics of children in influencing their chances to get into higher secondary schools are their aptitude as reflected in academic performance, especially in literacy and mathematics, as well as being well-adjusted in the classroom and conscientious with homework assignments. In the UK with the later transition into college-bound secondary education (around age 16), agency-related characteristics of the youth, such as career aspirations may well play a greater role for the transition outcome than in countries with early transitions (e.g., Switzerland, Germany).

Regarding tertiary education, characteristics of the youths' individual agency should have a greater effect on admission to university and success in completing a degree. The challenges to overcome are selection at admission to universities with advantages for higher SES youth in the US and UK (especially for elite colleges), and the financial burden associated with attending college (particularly in the US, not so much in Switzerland, Germany, and the UK). With regard to completing a degree, individuals with greater academic talent, but also those who are more goal directed, persistent, yet able to adjust goals (e.g., switch majors) if necessary, should stand a better chance, even if they are underprivileged to begin with.

\section{The Role of Social Capital in Upward Mobility in the Transition to Secondary Education in Switzerland}

Switzerland (similar to Germany) is a prime example of a structurally highly stratified system with segregated school institutions after an early transition between primary and secondary education (Buchmann et al. 2016). These systems with early transitions into secondary education typically give teachers and their recommendations for secondary school a decisive role, and thus the question becomes which factors play into teacher's judgements about a student's suitability for higher secondary education. Important factors are students' cognitive capabilities, as well as their non-cognitive conducive characteristics, such as conscientiousness, and work habits (Farkas et al. 1990). Interestingly, earlier research by Buchmann et al. (2016) suggested that cognitive ability of the child had a greater effect on accessing upper-secondary schools for lower class children compared to higher SES children, a finding contradicting the Scarr-Rowe hypothesis that capability differences can be developed better in upper SES families (Rowe et al. 1999; Scarr-Salapatek 1971). However, when educational opportunities are filtered via teacher recommendations, children's characteristics such as cognitive ability and good work habits may be construed more as a compensatory resource to make up for disadvantageous family 
background. In educational transitions that are teacherdominated, the various cognitive and personality characteristics of children play out not directly, but in the context of these teachers' belief systems about what makes a successful upper-secondary student. In these belief systems of teachers, children's characteristics may be seen as a potential compensatory factor for family disadvantage.

Buchmann and her colleagues illuminate the specific role of benevolent parent-teacher and student-teacher relationships in influencing teachers' recommendations for transition into secondary educational track. The advantage of the approach chosen by Buchmann and colleagues is that they contrast within the group of students from families with lower parental educational attainment, thus specifically pitching the youth who beat the odds, doing better than expected, and getting into the upper secondary educational track, against those who follow the more expected path of matching their parents' educational attainment. The pattern of findings provides clear support for the overwhelming influence of teachers. Secondary educational outcome was directly associated only with youths' cognitive abilities, parental educational aspirations, and cantonal baccalaureate rate. Everything else works either directly through the social relationships involving the teacher (teacher-parent, teacherstudent), and/or via teacher's assessment (of work habit, of students' self-assessment of work habit, or parent-teacher relationship, teacher-student relationship, parent-child as seen by child as seen by teacher). So, for all these noncognitive and social capital resources to make a difference, they have to be acknowledged by the teacher, and thus become accessible to influence the teachers' recommendation. In this context it is important to remember related but independent research evidence for the bias of teachers' recommendations towards advantaging children from higher SES (e.g., Lorenz et al. 2016), even though teachers compared to parents give actual school achievements a greater weight in determining their transition choices (Ditton and Krüsken 2006).

Two further aspects of these findings are noteworthy. First, when inspecting the items to assess "work habits" it is clear that they reflect goal engagement strategies (e.g., student tries very hard to do well in school; student is able to carry out his/her intentions; I do not abandon arduous tasks until they are completed) that may well function as a domain-general motivational trait (Heckhausen and Wrosch 2016). Such strong goal engagement strategies will be important tools for the individual well beyond educational contexts (Heckhausen et al. 2019). Certainly, they will prove to be helpful in pursuing a path that is not normative for one's social and educational background and thus requires more agentic goal pursuit capabilities.

Second, it is important to note that the one characteristic beyond the youths' intellectual capacity that stood out as effective and not mediated through teachers' influence was parental educational aspirations for their offspring. This converges with earlier research about the role of parents' expectations (Neuenschwander and Malti 2009), but goes beyond that by differentiating direct parent effects from those that are mediated via teachers. Holding high educational aspirations for their children is not typical for parents with lower educational attainment themselves, and other research has shown that less educated parents tend to have aspirations for their children that are less grounded in their actual school achievement and less congruent with teacher recommendations (Ditton et al. 2005). It would be important to know whether such incongruencies of parents' goals for their child's education were over- or under-aspirations. This underscores the need for further research to longitudinally disentangle the influences between child's schoolrelated behavior, actual school achievement and academic self-concept, parents' perceptions of child's capabilities and work habits (goal striving), and teachers' assessment of those child characteristics. With such data one could address questions like these: Who leads the way regarding the transition into secondary education? Who initiates a departure from a normatively expected path for a child from a lower educational background? Does it take a greater intervention effort for parents of lower SES to convince a teacher to change a recommendation upwardly versus downwardly?

\section{Individual Agency in the Transition to Tertiary Education in the United Kingdom: Probing Interactive Effects Between Social Background and Individual Agency}

There is some diversity of university access and cost in the United Kingdom, both geographically and in terms of elite compared to non-elite schools. Publicly funded universities and colleges in Scotland admit applicants from across the UK and Europe, but charge only the English, whereas in England and Wales universities charge fees from everyone of up to approximately $\$ 12,000$ per year. Access throughout the UK is regulated via predicted grades that an applicant's school (informed by previous grades and recent test scores and generated by teachers or counselors of the respective school) predicts the student will obtain. Hence, school performance as evaluated by teachers and counselors play a dominant role for admission, while cost is moderate compared to college cost in the United States.

Schoon and Cook's study investigates the predictive relationships between SES and a set of agency-related characteristics of youth when they were 14 years of age, and between these agency dimensions and the youths' admission (at age 20) and completion (at age 25) of tertiary educational degrees. The specific aspects of agency addressed are goal 
setting (for college admission), expected admission success, academic self-concept in disciplines (i.e., math, English, sciences, computing), and a measure of liking and being engaged in school.

The findings of the study provide evidence for pervasive SES differences in tendencies to apply for and expect success in higher education. However, when looking at agency dimensions that are more individual motivation-related, such as school engagement and academic self-concept, the associations with parental characteristics were only found for parents' education and not (or in the case of academic selfconcept, much less) for the income or vocational position of parents. It seems that the educational background of the family sets up a general attitude not just to attend higher education, but also to be personally committed and engaged with it. Mere social status and income does not do that, but merely creates a general expectation to get a tertiary degree.

Turning now to the effectiveness of agency, Schoon and Cook report evidence supporting an independent effect model, according to which individual differences of the youth in terms of the various agency characteristics had consistent associations with both the admission to and the completion of college. Both SES advantages and individual agency advantages enhanced the likelihood of attending university, which implies that agency resources could balance out or compensate some of the disadvantages of low SES. In terms of compensatory effectiveness of agency, even finding main-effect based evidence for the agency of individual youth being effective in overcoming the disadvantage of lower SES, demonstrates compensatory influence, even if the same agency also conveys benefits for higher SES youth. In other words, if you have a strong commitment to a goal of completing higher education in the UK, you can make it even if you come from a lower SES background. This is a causal pattern of multiple sufficient causes, both individual agency and high SES in themselves are sufficient causes for admission to and success in college.

In addition, and intriguingly, Schoon and Cook report evidence for so-called "compensatory effects" (i.e., differential effectiveness of agency in different SES groups) by identifying a significant interaction between school engagement and SES. This interaction indicates that youths' school engagement is particularly effective in bringing about university enrollment in lower SES youth, especially among women. This pattern of findings suggests that for higher SES youth, attending a university is more a default than the product of active agency and effort investment, whereas for lower SES youth it requires the youth's strong engagement with school. Looking at gender differences in this regard, it turns out that this interaction effect is present for both genders, but significant only in women.

Such an interaction effect of enhanced effectiveness of agency in lower SES youth was not found for the outcome of completing a degree. This is interesting because it supports the notion that once you enter university, SES differences are less influential in determining outcomes than they were before getting into tertiary education. The critical hurdle is college admission, after that your individual efforts are similarly effective in getting you to the degree, no matter whether you are high or low SES. You are advantaged if your parents have higher education and better vocational positions, but that does not modify the effectiveness of your engagement with academic matters.

An intriguing finding of Schoon and Cook's study was that the enrolled students with parents having higher educational degrees showed a much higher drop-out rate than youth of less educated parents. The analyses addressing interactions between socioeconomic risk and degree completion did not capture this phenomenon. They showed almost no significant interaction effects. Maybe what we are seeing here is that once youth from less educated backgrounds attain admission to university they do better than their more privileged counterparts, possibly because they represent a highly selected subgroup of youth that have superior agency characteristics. Such an agency-related selection effect converges with the so-called compositional effect in life-course sociological research on social mobility, according to which social status for more highly educated individuals (i.e., college degree) is decoupled from social status of family of origin (Hout 1988; see review in Pfeffer and Hertel 2015). If completion rates are higher among college students from lower educational backgrounds, the critical hurdle for attaining social mobility is getting into college in spite of disadvantages associated with family of origin. Whoever has the agentic capacity to take this hurdle in spite of a disadvantage in socioeconomic background may be more resilient against the challenges of college education, and maybe more likely to succeed in attaining a degree. This interpretation deserves more research and scrutiny to identify the specific agency processes involved in such resilience and identify where their potential and limits are in promoting upward mobility.

An aspect not investigated by Schoon and Cook, but likely somewhat influential for one's prospects to attain access to tertiary education in the UK, is the role of the teacher or school counselor who in the UK system of admission for tertiary education has to generate predicted grades for each high school graduate. I am not aware of evidence from the UK for systematic distortions of predicted grades associated with SES or educational background. However, a study on teachers' estimates of candidates' grades that distinguished between further education, secondary comprehensive, selective secondary, and independent (i.e., private elitist) institutions, found that more selective and especially elite institutions arrived at more accurate A-level grade predictions (predicted grades are a 
closer match to actually achieved grades) than comprehensive and especially further education schools (Dhillon 2005). Another study by Snell and colleagues directly addressing potential SES, minority and gender differences showed no social class or minority biases, a slight bias for underpredicting boys' grades effects, but similar to Dhillon's study they found differences between school types that reflect a consistent tendency of predicted grades to overestimate at higher score levels and underestimate at lower score levels (score-bias effect; Snell et al. 2008). So, we have here effectively another case of structural streaming in secondary schools, albeit more in terms of graded selectivity and less explicit than in the institutionally contrasting secondary school systems of Switzerland and Germany.

\section{Individual Agency Helps Young US Women More Than Young US Men to Overcome Lacking Parental Educational Background and Earn College Degrees}

The US tertiary educational system is highly stratified into elite and non-elite institutions, but graduating from college has become a highly normative expectation for young adults, with no institutional segregation into upper and lower tracks of secondary education as we find in Switzerland or Germany. However, students who are the first in their families to attend college, face greater obstacles in navigating the college admission system and the challenges associated with a college education itself. High-schools located in lower-class neighborhoods offer fewer opportunities for advanced placement classes and other learning contexts that foster high-levels of achievement in college admission tests (e.g., Kerckhoff 2001). Moreover, once admitted to college, first-generation students compared to continuing-generation students are more likely to drop out, take longer, and are less likely to earn college degrees (e.g., Ishitani 2006).

Under such challenging yet structurally relatively flexible circumstances, individual agency may be essential to overcome the obstacles to college admission and degree completion. Lee and Mortimer (2020) use an approach of direct comparison between successful and non-successful youth within a sample of young people with parents who did not earn a college degree (B.A.). This approach aims at identifying the individual characteristics at grade 10 of those youth who are doing better than expected based on their parents' educational attainment. Using structural equation modeling, the authors first identify a measurement model of agency that reflects a strong role of occupational/ economic self-efficacy, academic self-concept, and setting the goal of college graduation for oneself, with a lesser role for generalized perceptions of own control over one's life. In a second step the relationship of the thus composed agency variable with college graduation was assessed. The findings of this structural equation modeling suggest that individual agency as constituted by goals for tertiary educational attainment and academic as well as occupational/ economic (i.e., career-related) self-efficacy significantly contributes to predicting college graduation, and particularly for females. This type of analyzes does not allow us to conclude that either of these agency components are by themselves essential or whether they only work in combination with each other.

The closer association of agency characteristics with college graduation for women may be due to several circumstances as discussed by Lee and Mortimer. The idea that components of agency regarding self-assessments of mastery and control may more closely reflect actual abilities and skills in women compared to men, and may therefore be more predictive of ultimate academic success in earning a degree, makes the most sense to me. US female students may be more pragmatic in these self-assessments and less motivated by self-presentation and self-encouragement than US male students. Interestingly, the UK-based study by Schoon and Cook (2020) did not find such gender differences in predictiveness of goal setting and academic selfefficacy for college graduation, but did find that adolescent school engagement made a greater difference for low SES women compared to high SES women in predicting their enrollment in university.

\section{Agency Resources that Make a Difference for Upward Educational Mobility}

Pulling together what we discussed about the challenges of educational transitions and what we learned from the contributions for this special section on youth who are doing better in the educational systems of three countries than would be expected based on their socio-economic background, we can differentiate between basic agency resources and advanced or transformative agency. Basic agency resources comprise three individual difference dimensions. The first is of course intellectual ability, which is a resource for individual agency that is particularly relevant in an educational context. For the British Cohort Study, for example, Bourne and colleagues show that about half of the social origin effects on educational attainment are mediated via cognitive ability (Bourne et al. 2018). A recent analysis using a large sample of US students found that intellectual ability made more of a difference for longterm educational attainment among high-school students from higher SES families (also referred to as the Matthew effect or the Scarr-Rowe hypothesis) compared to lower SES families (Damian et al. 2015).

A second basic resource for individual agency in education is the absence of behavioral problems as indicated, for instance, by low neuroticism or the absence of ADHD symptoms. Such traits can be expected to be particularly 
relevant for educational transitions that are strongly influenced by teachers, with the transition into secondary education in Germany and Switzerland a case in point. Buchmann et al. (2020) did not specifically address these, but their predictive variable of supportive teacher-student relationship suggests that student problem behavior would be detrimental to attaining the teacher's recommendation for transition into an upper-level secondary school.

A third basic resource for agency is effective goal striving for specific academic goals such as getting a good grade, doing well on an exam. The achievement striving component of conscientiousness may play a major role here (Richardson and Abraham 2009). Interestingly, Buchmann and colleagues did not find direct effects of academic goal pursuit (they refer to them as work habits) on students' success into transitioning to an upper-level secondary school. Instead, they found that the teacher's perception of student's work habits was critical for their recommendation. In contrast, when it comes to transition into and persistence to graduation in tertiary education, goal setting, and striving as reflected in school engagement (Schoon and Cook 2020) become critical for predicting outcomes, but even there, SES advantages were significant predictors too. Most notably, individual goal engagement can be more effective for lower SES students and for attaining those outcomes (e.g., earning a tertiary degree) that require consistent personal and behavioral investment of the individual student, and not just normative expectations of a family with a more elitist educational background.

In contrast to these basic resources of agency, advanced and transformative agency is directed at pushing the longerterm life-course outcomes out of its normative track. This transformative agency becomes relevant in the transition to tertiary education for young people from lower educational backgrounds. Advanced agency strategies comprise a variety of motivational self-regulatory processes (Heckhausen and Wrosch 2016, Ng-Knight and Schoon 2017), only some of which were addressed in the relevant articles in this special section. The key process involved in advanced agency is the setting of goals that reach beyond the horizon of current and normative expectations. Setting ones' goals to higher education and professional careers as the first in one's family requires advanced transformative agency as addressed in the articles by Schoon and Cook and Lee and Mortimer. The two studies address goal setting as educational plans (Lee and Mortimer 2020) and as the statement that one is likely to apply for admission to higher education (Schoon and Cook 2020). A second important aspect of advanced agency is optimistic expectancies about reaching one's goal once a decision about an ambitious goal has been made. Schoon and Cook show for the UK sample significant effects of success expectations and academic self-concept, while Lee and Mortimer include perceptions of being in control of important outcomes in one's life (labeled as "mastery") as well as academic self-concept and economic self-efficacy in their predictive agency model for college graduation. Both studies show that goal setting and ambitious expectations can help youth overcome the constraints of a low education background. In addition, the British study was able to show that these effects are independent effects that are for the most part additive, except for the higher effectiveness of goal engagement in lower SES women for attaining a tertiary degree. With regard to the gender difference, this finding is convergent with the US-based study of Mortimer and Lee who showed that the effectiveness of agency characteristics differed by gender, with women benefitting more than men.

Another important strategy is the ability to calibrate one's developmental goals to the opportunities and constraints in the current developmental and social ecology, especially in response to failure experiences when striving for overly ambitious goals. This aspect was not addressed in the current set of studies. Yet another strategy that can prove to be critical when overcoming set-backs is to use volitional strategies to mobilize one's motivational commitment when boundary conditions are particularly challenging (see review in Heckhausen et al. 2019; also, Hamm et al. 2019; Poulin and Heckhausen 2007). Finally, a key transformative agency strategy especially in the context of developmental goal pursuit for upward mobility is to select one's social contexts (e.g., friends, activities, work context, neighborhood) so as to be promotive to one's active goal striving. Transforming one's own social ecology to scaffold an ambitious upward mobility goal can be extremely helpful for long-term and persistent goal pursuit. It has the potential of freeing the individual from having to continuously engage in volitionally costly self-direction and set up social prompts, models and guidelines to follow a transformative life-course trajectory for the better (Heckhausen and Heckhausen 2018).

\section{Conclusion}

Individual agency has increasing influence on social mobility the later in educational career paths individuals are segregated into upper and lower SES segments of society. The earlier transitions into secondary school are dominated by teachers and parents, with individual capacities of the student and motivational variables playing a role that is differential depending on social origin. Transitions into tertiary education allows for a greater influence of individual capacity and agency, such that it can compensate for disadvantages due to SES in the sense of providing a sufficient cause for college enrollment (UK) or college success (USA) even in the absence of SES advantages. It is useful to differentiate between different resources of individual agency, including intellectual abilities, socially acceptable behavioral and self-regulation, 
effective goal striving, and transformative agency (overcoming constraints of normative paths). For upward mobility all four resources need to be available to the individual. There is some initial evidence that agency effects are more pronounced in women compared to men. Finally, initial empirical findings suggest that once an individual has reached tertiary education, the detrimental effects of low SES and particularly of low-education social origin give more and more way to the influence of individual agency.

\section{Compliance with Ethical Standards}

Conflict of Interest The author declares no conflict of interest.

Publisher's note Springer Nature remains neutral with regard to jurisdictional claims in published maps and institutional affiliations.

\section{References}

Becker, R., \& Hecken, A. E. (2009). Higher education or vocational training? An empirical test of the rational action model of educational choices suggested by Breen and Goldthorpe and Esser. Acta Sociologica, 52, 25-45. https://doi.org/10.1177/0001699308100632.

Breen, R., \& Goldthorpe, J. H. (2001). Class, mobility, and merit: the experience of two British birth cohorts. European Sociological Review, 17, 81-101. https://doi.org/10.1093/esr/17.2.81.

Buchmann, M., Kriesi, I., Bayard, S., Sander, F., \& Bundel, S. (2020, this volume). Educational upward mobility in a stratified education system: social relationship quality and teacher assessment of student agentic capabilities. Journal of Youth and Adolescence.

Buchmann, M., Kriesi, I., Koomen, M., Imdorf, C., \& Basler, A. (2016). Differentiation in secondary education and inequality in opportunities. The case of Switzerland. In H.-P. Blossfeld, S. Buchholz, J. Skopek, \& M. Triventi (Eds.), Models of secondary education and social inequality: an international comparison. (pp. 111-128). Cheltenham, UK: Edward Elgar.

Bourne, M., Bukodi, E., Betthäuser, B., \& Goldthorpe, J. H. (2018). "Persistence of the social": the role of cognitive ability in mediating the effects of social origins on educational attainment in Britain. Research in Social Stratification and Mobility, 58, 11-21. https://doi.org/10.1016/j.rssm.2018.09.001.

Damian, R. I., Su, R., Shanahan, M., Trautwein, U., \& Roberts, B. W. (2015). Can personality traits and intelligence compensate for background disadvantage? Predicting status attainment in adulthood. Journal of Personality and Social Psychology, 109, 473-489. https://doi.org/10.1037/pspp0000024.

Diewald, M. (2016). Life course risk and welfare states' risk management. In M.J. Shanahan, J. Mortimer, \& M. Johnson (Eds.), Handbook of the life course (pp. 677-687). Cham: Springer International Publishing.

Dhillon, D. (2005). Teachers estimates of candidates' grades; curriculum 2000 advanced level qualifications. British Educational Research Journal, 31, 69-88. https://doi.org/10.1080/0141192052000310038.

Ditton, H., \& Krüsken, J. (2006). Transition from primary to secondary school. Zeitschrift für Erziehungswissenschaft, 9, 348-372.

Ditton, H., Krüsken, J., \& Schauenberg, M. (2005). Educational inequality-the influence of family and school. Zeitschrift für Erziehungswissenschaft, 8, 285-304.

Farkas, G., Grobe, R. P., Sheehan, D., \& Shuan, Y. (1990). Cultural resources and school success. Gender, ethnicity, and poverty groups within an urban school district. American Sociological Review, 55, 127-142. https://doi.org/10.2307/2095708.

Hahn, S. (2016). The risk of downward mobility in educational attainment: children of higher-educated parents in Germany. Wiesbaden: Springer.

Hamm, J. M., Perry, R. P., Chipperfield, J. G., Parker, P. C., \& Heckhausen, J. (2019). A motivation treatment to enhance goal engagement in online learning environments: assisting failureprone college students with low optimism. Motivation Science, 5, 116-134. https://doi.org/10.1037/mot0000107.

Heckhausen, J. (2016). Social inequality across the life course: societal unfolding and individual agency. In M. Buchmann, R. Scott \& S. Kosslyn (Eds.), Emerging trends in the social and behavioral sciences (pp. 1-18). Hoboken, NJ: Wiley.

Heckhausen, J., \& Buchmann, M. (2019). A multi-disciplinary model of life-course canalization and agency. Advances in Life Course Research, 41, 1-9. https://doi.org/10.1016/j.alcr.2018.09.002.

Heckhausen, J., \& Heckhausen, H. (2018). Development of motivation. In: J. Heckhausen \& H. Heckhausen (Eds.), Motivation and action (pp. 679-743), New York, NY: Springer.

Heckhausen, J., \& Wrosch, C. (2016). Challenges to developmental regulation across the life course: what are they and which individual differences matter? International Journal of Behavioral Development, 40, 145-150. https://doi.org/10.1177/0165025415588796.

Heckhausen, J., Wrosch, C., \& Schulz, R. (2010). A motivational theory of life-span development. Psychological Review, 117, 32-60. https://doi.org/10.1037/a0017668.

Heckhausen, J., Wrosch, C., \& Schulz, R. (2019). Agency and motivation in adulthood and old age. Annual Review of Psychology, 70, 191-217. https://doi.org/10.1146/annurev-psych010418-103043.

Hout, M. (1988). More universalism, less structural mobility. The American occupational structure in the 1980s. American Journal of Sociology., 93, 1358-1400. https://doi.org/10.1086/228904.

Ishitani, T. T. (2006). Studying attrition and degree completion behavior among first-generation college students in the United States. The Journal of Higher Education, 77, 861-885. https:// doi.org/10.1080/00221546.2006.11778947.

Kerckhoff, A. C. (2001). Education and social stratification processes in comparative perspective. Sociology of Education, 74, 3-18. https://doi.org/10.2307/2673250.

Knoemacom, (2020). World Data Atlas Rankings Gini Index. https:// knoema.com/atlas/ranks/GINI-index.

Krishna, A. (2014). Examining the structure of opportunities and social mobility in India: who becomes an engineer? Development and Change, 45, 1-28. https://doi.org/10.1111/dech.12072.

Lee, M., \& Mortimer, J.T. (2020, this volume). Believing and achieving: gendered pathways toward upward educational mobility in the United States. Journal of Youth and Adolescence.

Littler, J. (2017). Against meritocracy: culture, power, and myths of mobility. London, UK: Routledge.

Lorenz, G., Gentrup, S., Kristen, C., Stanat, P., \& Kogan, I. (2016). Teachers' stereotypes: an investigation of systematic bias in teachers' expectations. Kölner Zeitschrift für Soziologie und Sozialpsychologie, 68, 89-111. https://doi.org/10.1007/s11577015-0352-3.

Neuenschwander, M. P., \& Malti, T. (2009). Selektionsprozesse beim Übergang in die Sekundarstufe I und II. Zeitschrift für Erziehungswissenschaft, 12, 216-32.

Ng-Knight, T., \& Schoon, I. (2017). Can locus of control compensate for socioeconomic adversity in the transition from school to work? Journal of Youth and Adolescence, 46, 2114-2128. https:// doi.org/10.1007/s10964-017-0720-6.

OECD data, see Figure 1. https://data.oecd.org/inequality/incomeinequality.htm. 
Pfeffer, F. T., \& Hertel, F. R. (2015). How has educational expansion shaped social mobility trends in the United States? Social Forces, 94, 143-180. https://doi.org/10.1093/sf/sov045.

Poulin, M. J., \& Heckhausen, J. (2007). Stressful events compromise control strivings during a major life transition. Motivation and Emotion, 31, 300-311. https://doi.org/10.1007/s11031-007-9077-6.

Richardson, M., \& Abraham, C. (2009). Conscientiousness and achievement motivation predict performance. European Journal of Personality, 23, 589-605. https://doi.org/10.1002/per. 732.

Rowe, D. C., Jacobson, K. C., \& Van den Oord, E. J. C. G. (1999). Genetic and environmental influences on vocabulary IQ: parental education level as moderator. Child Development, 70, 1151-1162. https://doi.org/10.1111/1467-8624.00084.

Scarr-Salapatek, S. (1971). Race, social class, and IQ. Science, 174, 1285-1295. https://doi.org/10.1126/science.174.4016.1285.

Schoon, I., \& Cook, R. (2020, this volume). Can individual agency compensate for background disadvantage? Predicting educational attainment among men and women. Journal of Youth and Adolescence.

Schoon, I., \& Heckhausen, J. (2019). Conceptualizing individual agency in the transition from school to work: a social-ecological developmental perspective. Adolescent Research Review, 4, 135-148. https://doi.org/10.1007/s40894-019-00111-3.

Snell, M., Thorpe, A., Hoskins, S., \& Chevalier, A. (2008). Teachers' perceptions and A-level performance: is there any evidence of systematic bias? Oxford Review of Education, 34, 403-423. https://doi.org/10.1080/03054980701682140.

Jutta Heckhausen is a Professor at the University of California, Irvine in the Department of Psychological Science. Her major research interests include lifespan development, motivation, agency, life-course transitions (especially to adulthood), social mobility, social inequality, goal engagement, goal disengagement, action phases. 